\title{
Blood profile of broiler chickens fed diets supplemented with aged garlic extract or humates with probiotics at different growth stages
}

\author{
Honeylet J. Nicolas*
}

\begin{abstract}
The study was conducted to determine the effects of supplementing aged garlic extract (AGE) and humates with probiotics (HWP), at varying growth stages, on the blood profile of Cobb 500 broilers. The experiment followed the $4 \times 4$ factorial in Completely Randomized Design (CRD). The feed supplement was used as factor A (negative control, with AGE, with HWP, and positive control or antibacterial), and the different growth stage as the factor $B$ (brooder stage/0-12 d, starter stage/13$21 \mathrm{~d}$, grower stage/22-28 d, and brooder to grower stages/0-28 d). A total of 320 male day-old Cobb broiler chicks (DOC) were randomly distributed to 16 groups with four replicates each. The supplements were given at $1 \mathrm{~g} / \mathrm{kg}$ inclusion rate. Supplementation has no effect on the erythrocytic indices, specifically the RBC count, hemoglobin, packed cell volume (PCV), mean corpuscular volume (MCV), mean corpuscular hemoglobin $(\mathrm{MCH})$, and mean corpuscular hemoglobin concentration (MCHC). The results showed that with the supplementation of AGE and HWP, the erythrocytic indices were maintained within the physiological limits. Thus, AGE and HWP supplementation has no adverse effect on the blood profile of Cobb 500 broiler.
\end{abstract}

Keywords: aged garlic extract (AGE), broiler, humates, probiotics

\section{INTRODUCTION}

Profitability of poultry meat business largely depends on the management, performance and health status of birds. In the past, antibiotics were used not just to treat infectious diseases but also to improve the growth and productivity of animals. With the discovery of antimicrobial resistance in humans derived from consumption of antibiotic-laden animal food products, countries slowly shifted to alternative feed additives until antibiotic growth promotants were totally banned (Dankowiakowska et al 2013, Hughes \& Heritage 2004, Qamar et al 2015). Among the alternative feed additives used nowadays are phytogenics, humates, and probiotics.

"Institute of Agricuture, Bulacan Agricultural State College, San Ildefonso, Bulacan 3010, Philippines

* Corresponding Author. Address: Institute of Agricuture, Bulacan Agricultural State College, San Ildefonso, Bulacan 3010; e-mail: honeylet.vlv@gmail.com, honeylet_vlv@yahoo.com DOI: $10.32945 /$ atr 4014.2018 
Blood profile of broiler chickens fed diets supplemented with aged garlic extract or humates

Phytogenics or botanicals are plant-derived products including herbs, spices and essential oils. Garlic-based products are some of the most popular phytogenics in the market. Aged garlic extract (AGE) is a novel product from garlic that was derived from a special fermentation process. AGE contains organosulfur bioactive substances called thiosulfinate-cysteine compounds, which include Sallyl cysteine (SAC), S-methyl cysteine (SMC) and S-allyl mercaptocysteine (SAMC). These serve as precursors of amino-acids and help in the synthesis of proteins, enzymes, vitamins, and minerals. They have anti-microbial, anti-oxidant, immuno-modulatory, and metabolism-, production-, and reproduction-enhancing properties (Hossain 2014).

Humates or humic acids are naturally-occurring decomposed organic constituents of soil and lignite that are complex mixtures of polyaromatic and heterocyclic chemicals with multiple carboxylic acid chains (Islam et al 2005, Rath et al 2006). Humic acids have been used as antidiarrheal, analgesic, immunostimulatory, and antimicrobial agent in veterinary practices in Europe (EMEA 1999).

Probiotics are products containing useful bacteria or fungi. As dietary supplements, they affect higher performance in stressful situations and periods of decreased immune response (Dankowiakowska et al 2013). The mode of action of probiotics in poultry includes maintaining normal intestinal microflora by competitive exclusion and antagonism, altering metabolism by increasing digestive enzyme activity and decreasing bacterial enzyme activity and ammonia production, improving feed intake and digestion, and neutralizing enterotoxins and stimulating the immune system (Král et al 2012).

Blood profiles of animals can indicate the presence of metabolites, toxicants and other conditions (Doyle 2006, Khan \& Zafar 2005). They are good indicators of the nutritional, physiological and pathological status of animals, and can be useful in the diagnosis and prognosis of diseases (Etim et al 2014). This study was therefore designed to determine the effects of dietary supplementation, at varying growth stages, of aged garlic extract (AGE) and humates with probiotics (HWP) on the blood erythrocytic profile of broilers.

\section{MATERIALS AND METHODS}

\section{Experimental Design}

This study used $4 \times 4$ factorial in a Completely Randomized Design (CRD). A total of 320 day-old male chicks of Cobb 500 strain, were distributed to 16 groups with four replicates each, and with five birds per replicate. Factor A (feed supplement) included: A1) NC - basal diet; A2) with AGE - basal diet + aged garlic extract (AGE) product (1 g/kg feed); A3) with HWP - basal diet + probiotics and humates with probiotics (HWP) product ( $1 \mathrm{~g} / \mathrm{kg}$ feed); and A4) with ABP - basal diet + antibacterial product: tiamulin hydrogen fumarate and doxycycline hydrochloride (1 g/kg feed). Factor B (growth stage), included: B1) Brooder stage - 0 to 12 days; B2) Starter stage - 13 to 21 days; B3) Grower stage - 22 to 28 days; and $B 4)$ Brooder to Grower stages -0 to 28 days. Thus, the 16 groups were: $A 1 B 1$, A1B2, A1B3, A1B4, A2B1, A2B2, A2B3, A2B4, A3B1, A3B2, A3B3, A3B4, A4B1, A4B2, $A 4 B 3$, and $A 4 B 4$. During the finisher stage (29-35 days), the birds received a uniform diet. 


\section{Management of Experimental Birds}

The experimental housing had a slatted floor made of plastic crates, and a monitor-type galvanized iron roof. A designated pen was assigned in different groups and were properly labelled. On the first 7 days, 24 -hr light was provided and was reduced to 18 -hr per day on the $8^{\text {th }}$ to $12^{\text {th }}$ day. The average temperature was $32^{\circ} \mathrm{C}$ and was reduced depending on the behavior of the flock. Rice hull on old newspapers were used as litter materials during brooding and was replaced daily. On day $13^{\text {th }}$ day, the brooding was stopped and all litter materials were removed.

Booster mash was given during the first 12 days, while starter crumble was given at days 13 to 21 . Grower crumble was given on day 22 to day 28 , and finisher feeds at day 29 to 35 . Clean water and feeds were given ad libitum. Shifting from one type of feeds to another was done gradually. The feed supplements were given as indicated in the treatment group of the birds.

\section{Blood Profiling}

Blood samples were collected on day 30 for the blood profiling of chickens, using two samples per group for a total of 32 samples. Sterile vacutainers with disodium ethylenediaminetetraacetic acid (EDTA) as anticoagulant was used. Blood was collected from the wing vein and lateral saphenous vein using aseptic technique. The analysis was carried out in the RADDL using the Celltac ${ }^{\oplus}$ Hematology Analyzer MEK- 6550 by Nihon Kohden. The blood parameters that were determined include: red blood cell (RBC) count, total white blood cell (WBC) count, hemoglobin $(\mathrm{Hb})$ concentration, hematocrit level, mean corpuscular volume (MCV), mean corpuscular hemoglobin ( $\mathrm{MCH})$, and mean corpuscular hemoglobin concentration (MCHC).

\section{Statistical Analysis}

Results were analyzed using analysis of variance (ANOVA) and differences among treatments were compared using Duncan's Multiple Range Test (DMRT). The GraphPad Prizm Matrix and Statistical Tool for Agricultural Research (STAR), 2015 Version statistical tools were used.

\section{RESULTS AND DISCUSSION}

The different erythrocytic values obtained in the study were red blood cell/RBC $\left(\mathrm{x} 10^{6} / \mu \mathrm{L}\right)$, hemoglobin/Hgb $(\mathrm{g} / \mathrm{dL})$, packed cell volume/PCV $(\%)$, mean corpuscular volume/MCV ( $\mathrm{fL})$, mean corpuscular hemoglobin/ $\mathrm{MCH}(\mathrm{pg})$ and mean corpuscular hemoglobin concentration/MCHC (pg). The references available for chicken standard blood values do not distinguish between broiler and layer types as well as other physiological or ecological factors (Reece 2015, Talebi et al 2005). 
Blood profile of broiler chickens fed diets supplemented with aged garlic extract or humates

Table 1. Specific erythrocytic values at day 30 of broilers given with feed supplements containing HWP and AGE in different growth stages.

\begin{tabular}{|c|c|c|c|c|c|}
\hline \multirow{2}{*}{$\begin{array}{l}\text { Factor A- } \\
\text { Feed } \\
\text { supplement }\end{array}$} & \multirow[b]{2}{*}{$\begin{array}{l}\text { Reference } \\
\text { Values } \\
\text { (Talebi et al } \\
2005 * \\
\text { Reece } \\
2015 * \star \text { ) }\end{array}$} & \multicolumn{4}{|c|}{ Factor B - Growth Stage of Birds } \\
\hline & & $\begin{array}{c}\text { B1 - } \\
\text { brooder } \\
(0-12 d)\end{array}$ & $\begin{array}{c}\text { B2 - starter } \\
(13-21 \mathrm{~d})\end{array}$ & $\begin{array}{c}\text { B3 - grower } \\
(22-28 d)\end{array}$ & $\begin{array}{c}\text { B4 -brooder } \\
\text { to grower } \\
(0-28 d)\end{array}$ \\
\hline \multicolumn{6}{|c|}{ Red Blood Cell, RBC $\left(x 10^{6} / \mu \mathrm{L}\right)$} \\
\hline $\mathrm{A} 1-\mathrm{NC}$ & $1.89-3.21 *$ & 2.10 & 2.76 & 2.35 & 2.54 \\
\hline $\mathrm{A} 2-\mathrm{AGE}$ & $3.0 * *$ & 2.32 & 2.04 & 2.40 & 2.37 \\
\hline A3 - HWP & & 2.05 & 2.69 & 2.32 & 2.61 \\
\hline $\mathrm{A} 4-\mathrm{ABP}$ & & 2.75 & 1.95 & 1.94 & 2.12 \\
\hline \multicolumn{6}{|c|}{ Hemoglobin, Hgb (g/dL) } \\
\hline $\mathrm{A} 1-\mathrm{NC}$ & $6.83-16.26 *$ & 9.7 & 13.2 & 10.8 & 11.7 \\
\hline $\mathrm{A} 2-\mathrm{AGE}$ & $9.0 * *$ & 11.0 & 9.5 & 11.3 & 11.0 \\
\hline A3 - HWP & & 9.9 & 12.9 & 10.9 & 12.1 \\
\hline $\mathrm{A} 4-\mathrm{ABP}$ & & 12.7 & 9.7 & 9.5 & 10.3 \\
\hline \multicolumn{6}{|c|}{ Packed Cell Volume, PCV (\%) } \\
\hline $\mathrm{A} 1-\mathrm{NC}$ & 26.46- & 27.7 & 39.1 & 31.3 & 36.5 \\
\hline $\mathrm{A} 2-\mathrm{AGE}$ & 39.03* & 32.3 & 29.0 & 33.8 & 32.6 \\
\hline A3 - HWP & $30.0 * *$ & 29.5 & 37.6 & 32.5 & 35.6 \\
\hline$A 4-A B P$ & & 38.1 & 28.7 & 28.4 & 30.1 \\
\hline \multicolumn{6}{|c|}{ Mean Corpuscular Volume, MCV (fL) } \\
\hline $\mathrm{A} 1-\mathrm{NC}$ & $111.0-$ & 132.0 & 142.0 & 133.0 & 144.0 \\
\hline $\mathrm{A} 2-\mathrm{AGE}$ & $149.5 *$ & 139.0 & 142.0 & 141.0 & 138.0 \\
\hline A3 - HWP & $115.0 * *$ & 144.0 & 140.0 & 140.0 & 136.0 \\
\hline $\mathrm{A} 4-\mathrm{ABP}$ & & 139.0 & 147.0 & 146.0 & 142.0 \\
\hline \multicolumn{6}{|c|}{ Mean Corpuscular Hemoglobin, $\mathrm{MCH}(\mathrm{pg})$} \\
\hline $\mathrm{A} 1-\mathrm{NC}$ & $31.13-60.5^{*}$ & 46.2 & 47.8 & 46.0 & 46.1 \\
\hline $\mathrm{A} 2-\mathrm{AGE}$ & $41.0 * *$ & 47.4 & 46.6 & 47.1 & 46.4 \\
\hline A3 - HWP & & 48.3 & 48.0 & 47.0 & 46.4 \\
\hline $\mathrm{A} 4-\mathrm{ABP}$ & & 46.2 & 49.7 & 49.0 & 48.6 \\
\hline \multicolumn{6}{|c|}{ Mean Corpuscular Hgb Concentration, $\mathrm{MCHC}$ ( $\mathrm{g} / \mathrm{dL}$ or $\mathrm{gm} \%)$} \\
\hline$A 1-N C$ & $22.0-50.0 *$ & 35.0 & 33.8 & 34.5 & 32.1 \\
\hline $\mathrm{A} 2-\mathrm{AGE}$ & $29.0 * *$ & 34.1 & 32.8 & 33.4 & 33.7 \\
\hline A3 - HWP & & 33.6 & 34.3 & 33.5 & 34.0 \\
\hline $\mathrm{A} 4-\mathrm{ABP}$ & & 33.3 & 33.8 & 33.5 & 34.2 \\
\hline
\end{tabular}

NC - negative control group (basal diet);

HWP - basal diet + probiotics and humic-fulvic acids (PHFA) product (1 $\mathrm{g} / \mathrm{kg}$ feed);

AGE - basal diet + aged garlic extract (AGE) product ( $1 \mathrm{~g} / \mathrm{kg}$ feed);

ABP - basal diet + tiamulin and doxycycline $(1 \mathrm{~g} / \mathrm{kg})$ 
The health status can be inferred from the erythrocytic values of an animal (Etim et al 2014). Anemia is defined as the reduction below normal of the number of erythrocytes (RBCs), and/or hemoglobin concentration (Reece 2005). The recorded values of 1.94-2.76 million per microliter $\left(10^{6} / \mu \mathrm{L}\right)$ from the experimental birds are within the range of RBC count of broiler strains $\left(1.89-3.2110^{6} / \mu \mathrm{L}\right)$ according to Talebi et al (2005).

Hemoglobin is a complex molecule containing four amino acid chains (globin portion) held together by noncovalent interactions (Frandson et al 2010). Hemoglobin transports $\mathrm{O}_{2}$ from lungs to tissues and plays major roles in the transport of $\mathrm{CO}_{2}$ from tissues to lungs (Reece 2005). Hemoglobin counts of the experimental birds in grams per decilitre $(\mathrm{g} / \mathrm{dL})$ are also near the values suggested by Talebi et al (2005) as well as that of Reece (2015). This may imply that supplementation with probiotics and humic-fulvic acids as well as aged garlic extract had no adverse effect on the RBC and hemoglobin counts of broilers.

The packed cell volume (PCV) is the percentage of the volume of whole blood that is erythrocytes (Frandson et al 2010). It is expressed as percentage (\%). Abnormal increase in PCV indicates dehydration. The results on PCV of the experimental birds, ranging from $27.7 \%$ to $39.1 \%$, also suggest normal PCV according to Reece (2015) and Talebi et al (2005).

Two features of RBCs are used to classify an anemia on a morphologic basis their size and hemoglobin content. The size is expressed as mean corpuscular volume (MCV), which is determined by dividing the PCV in percent by the erythrocyte count in millions per cubic $\mathrm{mm}$ and multiplying by 10 . The answer is expressed in femtoliters $(\mathrm{fL})$; femto is one-quadrillionth $\left(10^{-15}\right)$. Thus, if PCV is $42 \%$ and $\mathrm{RBC}$ count is $6 \mathrm{M} / \mu \mathrm{L}$, the $\mathrm{MCV}=(42 \%) / 7 \times 10=60 \mathrm{fL}$. Increased MCV indicates macrocytic anemia, or presence of larger immature RBCs, usually due to disorders of accelerated erythropoiesis (Jones et al 1997, Reece 2005, Reece 2015, Stockham \& Scott 2002). The MCV results of the experimental birds, ranging from 132 to $147 \mathrm{fL}$, are also within the normal range for broilers using the values suggested by Talebi et al (2005).

The hemoglobin content of the RBC is expressed as the mean corpuscular hemoglobin concentration ( $\mathrm{MCHC}$ ), which is determined by dividing the hemoglobin in grams per $100 \mathrm{~mL}$ of blood by the PCV in percent and multiplying by 100. The answer is expressed as percent hemoglobin per cell. For example, for a hemoglobin of $14 \mathrm{gm} \%$ and PCV of 42 , the MCHC is $14 / 42 \times 100=33.3 \%$, the generally accepted normochromic. Based on $\mathrm{MCHC}$, anemias can be classified as either normochromic (normal) or hypochromic (decreased). Hyperchromic anemias do not exist in that there is a limit to the percentage of hemoglobin that can exist in an erythrocyte (Jones et al 1997, Reece 2015, Stockham \& Scott 2002). $\mathrm{MCHC}$ results of the experimental birds suggest that their RBCs have normal hemoglobin contents.

The amount of hemoglobin per RBC is termed mean corpuscular hemoglobin $(\mathrm{MCH})$, expressed in picograms or $\mathrm{pg}$ (pico is one-trillionth, $10^{-12}$ ) and is calculated by dividing hemoglobin in grams per $100 \mathrm{~mL}$ of blood by RBCs in millions per cubic $\mathrm{mm}$ and multiplying by 10 (Reece 2005). For example, for $14 \mathrm{gm} / \mathrm{dL}$ hemoglobin and an erythrocytic count of $7 \mathrm{M} / \mu \mathrm{L}$, the $\mathrm{MCH}$ is 20pg. However, in the classification of anemias, $\mathrm{MCH}$ is not used to determine hypochromasia or normochromasia. 
Blood profile of broiler chickens fed diets supplemented with aged garlic extract or humates

All these results on the blood profile agree with the results of Elagib et al (2013) that garlic supplementation had no adverse effects on the blood profile of broilers, but do not concur with Jameel et al (2014) whose study reported an increase RBC, $\mathrm{PCV}$ and $\mathrm{Hb}$ due to garlic supplementation. The results also agree with Akhalf et al (2010) that probiotics supplementation had no effect on $\mathrm{Hb}$ and PCV, and other blood parameters. Rath et al (2006) also reported that supplementation with humates had no adverse effect on the blood profile of broiler chickens.

\section{CONCLUSION}

Based on the results of this study, AGE and HWP supplementation, regardless of the growth stage has no effect on the hematological profile of broilers specifically on the red blood cell count (RBC), hemoglobin ( $\mathrm{Hgb})$, packed cell volume (PCV), mean corpuscular volume (MCV), mean corpuscular hemoglobin $(\mathrm{MCH})$, and mean corpuscular hemoglobin concentration (MCHC). Thus, AGE or HWP supplementation has no adverse effect on the blood profile since the indices were maintained within the normal physiological limits of the birds.

\section{REFERENCES}

Alkhalf A, Alhaj M \& Alhamidan L. 2010. Influence of probiotic supplementation on blood parameters and growth performance in broiler chickens. Saudi $J$ Biological Science, 17:219-225.

Dankowiakowska A, Kozlowska I \& Bednarczyk M. 2013. Probiotics, prebiotics and synbiotics in poultry - mode of action, limitation and achievements. $J$ Central European Agriculture, 14(1):467-478.

Doyle D. 2006. William Hewson (1739-74), The father of hematology. British $J$ Haematology, 133(4):375-381.

Elagib HAA, EL-Amin WIA, Elamin KM \& Malik HEE. 2013. Effect of dietary garlic (Allium sativum) supplementation as feed additive on broiler performance and immune response. J Animal Science Advances, 3(2):58-64.

EMEA. 1999. Humic acids and their sodium salts, summary report. Committee for Veterinary Medicinal Products, European Agency for the Evaluation of Medicinal Products. http://www.emea.eu.int/pdfs/vet/mrls/055499en.pdf. Accessed June 10, 2005.

Etim NAN, Williams ME, Akpabio U \& Offiong EEA. 2014. Haematological parameters and factors affecting their values. Agricultural Science, 2(1):3747.

Frandson RD, Wilke WL \& Fails AD. 2010. Anatomy and physiology of Farm Animals $\left(7^{\text {th }}\right.$ edn). Wiley-Blackwell.

Hossain MM, LeeSI \& Kim IH. 2014. Effect of dietary Korean aged garlic extract by Leukonostoc citreum SK2556 on production, hematological status, meat quality, relative organ weight, targeted Escherichia coli colony and excreta gas emission in broilers. Animal Feed Science \& Technology, 198:333-340.

Hughes $P$ and Heritage J. 2004. Antibiotic growth promoters in food animals. In Assessing quality and safety of animal feeds (pp129-152), Food and Agriculture Organization-Animal Production and Health Papers Series No160, 
Islam KMS, Schumacher A \& Group JM. 2005. Humic acid substances in agriculture. Pakistan J Nutrition, 4(3):126-134.

Jones TC, Hunt RD \& King NW. 1997. Veterinary Pathology. Williams and Wilkins,Pennsylvania.

Khan TA and Zafar F. 2005. Haematological study in response to varying doses of estrogen in broiler chicken. International J Poultry Science, 4(10):748-751.

Kral M, Angelovicova M \& Mrazova L. 2012. Application of probiotics in poultry production. Scientific papers, Animal Science \& Biotechnologies, 45(1):55-57.

Rath NC, Huff WE \& Huff GR. 2006. Effects of humic acid on broiler chickens. Poultry Science, 85:410-414.

Reece WO (ed). 2015. Duke's Physiology of Domestic Animals ( $13^{\text {th }}$ edn). John Wiley \& Sons, Inc., Oxford.

Reece WO. 2005. Functional Anatomy and Physiology of Domestic Animals ( $3^{\text {rd }}$ edn). Lippincott Williams and Wilkins, Baltimore, Maryland.

Stockham SL and Scott MA. 2002. Fundamentals of Veterinary Clinical Pathology. Blackwell Publishing Co., Ames, lowa.

Talebi A, Asri-Rezaei S, Rozeh-Chai R \& Sahrei R. 2005. Comparative studies on hematological values of broiler strains (Ross, Cobb, Arbor-Acres and Arian). International J Poultry Science, 4(8):573-579. 